\title{
Relationships between metabolic status, seminal adipokines, and reproductive functions in men from infertile couples
}

\author{
Yaelle Elfassy ${ }^{1,2}$, Alice Bongrani ${ }^{3}$, Pierre Levy ${ }^{4,5}$, Frantz Foissac ${ }^{6}$, Soraya Fellahi' ${ }^{2,7}$, Céline Faure ${ }^{1}$, Chloé McAvoy ${ }^{2}$, \\ Jacqueline Capeau ${ }^{2}$, Joëlle Dupont ${ }^{3}$, Bruno Fève ${ }^{2,8}$, Rachel Levy ${ }^{1,2}$ and Jean-Philippe Bastard ${ }^{2,7}$ on behalf of the \\ Metasperme group*
}

\begin{abstract}
${ }^{1}$ Assistance Publique des Hôpitaux de Paris, Hôpital Tenon, Service de Biologie de la Reproduction, Sorbonne Université, Paris, France, ${ }^{2}$ Sorbonne Université-INSERM UMR S_938, Centre de Recherche Saint-Antoine, IHU ICAN, Paris, France, ${ }^{3}$ INRA, UMR85, Physiologie de la Reproduction et des Comportements, Nouzilly, France, ${ }^{4}$ Assistance Publique des Hôpitaux de Paris, Hôpital Tenon, Unité de Santé Publique, Sorbonne Université-INSERM UMR S_1136, Paris, France, 5 Institut Pierre-Louis de Santé Publique (EPAR Team), Paris, France, ${ }^{6}$ Clinical Research Unit Necker-Cochin, Assistance Publique-Hopitaux de Paris, Paris, France, ${ }^{7}$ Assistance Publique des Hôpitaux de Paris, Hôpital Tenon, UF Biomarqueurs Inflammatoires et Métaboliques, Service de Biochimie et Hormonologie, Paris, France, and ${ }^{8}$ Assistance Publique des Hôpitaux de Paris, Hôpital Saint-Antoine, Service d'Endocrinologie, Paris, France

*(Details of the Metasperme group is presented in the Acknowledgements section)
\end{abstract}

\section{Correspondence} should be addressed to J-P Bastard Email jean-philippe.bastard@aphp.fr

\begin{abstract}
Objective: Adipokines could be a link between metabolic syndrome (MS) and infertility. While the association between circulating adipokines and fertility has been extensively studied in females, this relationship in males was less investigated, although some adipokines are detectable in seminal plasma (SP). The aim of this study was to determine adipokine levels in blood and SP and to assess the relationships between adipokines, MS and semen parameters in men from infertile couples.

Design: Male partners of infertile couples referred to four medical French centers were enrolled in years 2013-2016. Methods: Subjects ( $n=160$ ) aged 18-45 years were assessed for anthropometric, biochemical, sperm, and circulating hormonal parameters. Leptin, adiponectin, resistin, chemerin, visfatin, and IL-6 were measured in serum and SP. Results: Infertility duration was higher in men with than without MS. Adipokine concentrations were higher in blood than in SP, except for IL-6 and visfatin. The most striking result was the significant correlation observed between seminal IL- 6 and spermatozoid concentration, progressive motility, and sperm vitality. Moreover, while men with MS exhibited an expected lower adiponectinemia, they displayed 2.1-fold higher adiponectin levels in SP than men without MS. Finally, logistic regression analysis showed that BMI, infertility duration, and adiponectin serum/SP ratio were independently associated with MS.

Conclusions: These results suggest an involvement of seminal adipokines to modulate fertility in men with MS and that seminal IL-6 could play a beneficial role on sperm functionality. Further mechanistic studies are necessary to investigate the precise roles of these adipokines in male reproduction.
\end{abstract}

\section{Introduction}

Increased body weight is a worldwide concern (1): in 2016, $39 \%$ of adults over 18 years were overweight, and 13\% obese $(2,3)$. Metabolic syndrome (MS), defined by the

presence of three out of five features including abdominal adiposity and a cluster of cardiometabolic risk factors, is associated with an increased risk of multiple chronic 
diseases, including diabetes, cancer and cardiovascular diseases (4). MS prevalence is also increasing worldwide with a rise of $35 \%$ from 1988-1994 to 2007-2012 in the United States (4). Infertility is also a global public health problem as it affects one out of four couples in high and low-medium income countries (http://www.who.int/r eproductivehealth/topics/infertility/burden/en/). This could result from factors related only to women, in onethird of cases mostly ovulatory disorders or only to men in one-fifth of cases, with a decrease in semen parameters or both to women and men in $40-50 \%$ of cases $(5,6,7,8)$. A secular decrease of sperm concentration has been ongoing for the last decades in Western Europe $(9,10)$. While obesity has been clearly associated with reduced fertility in men (11), metabolic disorders, as seen in MS, are rarely considered in the current treatment of infertility. Even if low testosterone levels have been reported in subjects with MS $(12,13,14,15)$, studies that evaluated semen parameters in these subjects $(2,13,16$, $17,18,19)$ reported contradictory results. Therefore, the mechanisms underlying the relationships between MS and disturbed fertility remain unclear and multiple and complex interactions between some metabolic pathways and reproductive functions could exist.

The reproductive endocrine aspects of white adipose are now well accepted (20). In rats, the removal of the epididymal adipose tissue causes a significant decrease in sperm count (21). Adipose tissue-secreted hormones, known as adipokines, play an important role in the regulation of several major hormonal pathways such as the pituitary and reproductive axis. The levels of several circulating adipokines are related to BMI and also to semen parameters (22). Thus, obesity is associated with hyperleptinemia and leptin resistance (23), whereas adiponectinemia is negatively associated with BMI (24). Several adipokines are involved in the regulation of the reproductive axis, with correlations between the levels of circulating adipokines and semen parameters. It has been shown that leptinemia was positively related to abnormal sperm morphology, and negatively to both sperm concentration and motility $(25,26)$. Therefore, reduced fertility in MS men could be partly related to the high levels of circulating leptin, leading to a decreased testosterone production by Leydig cells, which interferes with the normal cycle of spermatogenesis (27). Otherwise, studies performed in bulls showed that circulating adiponectin levels were related to sire conception rates (28).

In addition, adipokines are present in the seminal plasma (SP), and also inside germ cells (29), raising the possibility that they can also directly act on gonadic cells to modulate their functions, and in turn fertility. However, relationships between adipokines in the SP and fertility have been poorly studied. More investigation is required to decipher their pathophysiological roles and to identify new potential targets to improve male fertility. Thus, the aim of this study was to determine adipokine levels in blood and semen and to assess the relationships between adipokines, MS and semen parameters in a population of men issued from infertile couples.

\section{Patients and methods}

\section{Patients}

The multicentric and transversal Metasperme study (Biomedical Research AOM 10020 - NI 10033 - ID-RCB 2011-A01052-3), was performed from July 2013 to January 2016 by consecutive inclusions of male partners of infertile couples. The present work on blood and semen adipokines corresponds to an ancillary study from this cohort. Four medical French centers included male partners aged 18-45 years from infertile couples, with primary or secondary infertility for at least 12 months. Exclusion criteria were difficulties to understand, seropositivity for HIV, HBV or HCV, smoking more than 40 cigarettes a day as well as male explained infertility (for example after chemotherapy, varicocele or genital surgeries). Participants gave full informed written consent to participate in the study and ethical approval was obtained from the Ethics Committee of the University of Paris Ile-De-France IV.

\section{Clinical and biological measurements}

We measured weight, height, waist circumference (WC), hip circumference according to WHO guidelines (30), and blood pressure (BP). Infertility duration was defined by the time between the beginning of regular unprotected sexual intercourses and the day of inclusion. Ejaculated semen samples were collected after 3-5 days of sexual abstinence. Sperm parameters namely volume, $\mathrm{pH}$ of the ejaculate, sperm count, motility and vitality were analyzed according to bioforma (31) adapted from WHO guidelines (32) (Supplementary Table 1, see section on supplementary materials given at the end of this article). Semen was kept for 20-60 min for liquefaction. Then, semen volume and $\mathrm{pH}$ were measured and recorded. Semen samples were evaluated for motility in duplicates according to standard WHO guidelines (32). Sperm numeration was obtained manually in duplicates by Kova chamber counting. 
Sperm vitality was assessed by eosin-nigrosin staining on 100 sperm. Sperm morphology was evaluated after Harris-Schorr staining using modified David's score (33). Remaining semen was centrifuged at $600 \boldsymbol{g}$ for $10 \mathrm{~min}$. Aliquots were stored at $-80^{\circ} \mathrm{C}$ until assay analysis. Fasting blood samples were centrifuged at $1900 \boldsymbol{g}$ for $10 \mathrm{~min}$, serum was aliquoted and kept at $-80^{\circ} \mathrm{C}$ until use.

Sex hormone-binding globulin (SHBG) was measured on Access analyzer (Beckman Coulter). Total testosterone was measured by RIA (Beckman Coulter - Immunotech, Marseille, France). Bioavailable testosterone was measured after ammonium sulfate precipitation as previously described $(34,35)$. Follicle-stimulating hormone (FSH), luteinizing hormone (LH), inhibin B, estradiol, glucose, triglycerides, total and HDL cholesterol, insulin, and C-reactive protein (CRP) were routinely measured on Cobas analyzer (Roche Diagnostics). The insulin resistance HOMA-IR index was calculated as (glycemia $(\mathrm{mmol} / \mathrm{L}) \times$ insulinemia $(\mathrm{mU} / \mathrm{L}) / 22.5)(36)$.

Adipokine measurements from frozen samples were performed in both semen plasma and serum according to pre-analytical conditions previously described (37). Leptin (blood, SP), adiponectin (SP), resistin (blood, SP), chemerin (blood, SP) and IL-6 (blood, SP) were measured by ELISA (Quantikine R\&D Sytems). Biovendor (Brno, Czech Republic) and ALPCO were used for ELISA measurements of visfatin (blood, SP) and adiponectin (blood), respectively. In serum, intra-assay and inter-assay coefficients of variations were under $8 \%$ and in SP, intra-assay coefficients of variations were under $6 \%$ and inter-assay coefficients of variations under 10\% (37).

\section{Metabolic syndrome classification}

MS was defined according to the harmonized classification of 2009 (38) by the presence of at least three of the five following criteria: $\mathrm{WC} \geq 94 \mathrm{~cm}$, systolic $\mathrm{BP} \geq 130 \mathrm{mmHg}$ and/or diastolic blood pressure $\geq 85 \mathrm{mmHg}$ and/or antihypertensive treatment, triglyceride levels $\geq 1.7 \mathrm{mmol} / \mathrm{L}$ and/or taking a specific treatment, glycemia $\geq 5.6 \mathrm{mmol} / \mathrm{L}$ and/or taking anti-diabetic treatment, HDL cholesterol level $<1.03 \mathrm{mmol} / \mathrm{L}$. One hundred seventy patients were selected for the study, whilst seven were excluded. Of the 134 patients for whom all the required criteria were available, 42 patients were diagnosed with MS and 92 without. Of the 29 subjects with missing data, those who had at least three positive criteria were considered with MS $(n=5)$ and those who had at least three negative criteria were classified without MS $(n=24)$. Thus, only three patients could not be included regarding their MS status (Fig. 1).

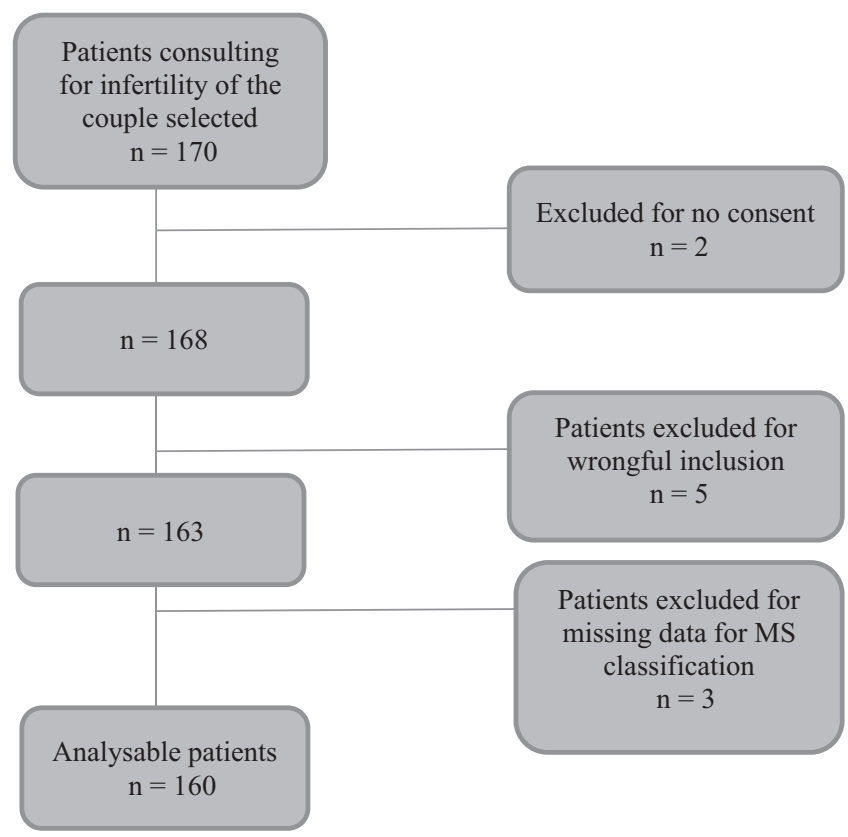

\section{Figure 1}

Flow chart.

\section{Statistical analysis}

We used StatView software (SAS Institute, Inc, copyright 1992-1998). Qualitative variables were analyzed using chi-square test or when appropriate, Fisher's exact test. Quantitative variables were analyzed using the nonparametric Mann-Whitney test, the Wilcoxon rank test and the Spearman correlation coefficient. Descending stepwise logistic regression analyses were used to identify the independent variables associated to MS. This analysis was performed in 126 subjects for whom all logistic regression parameters (age, infertility time, sperm concentration, BMI, SHBG, total testosteronemia, inhibin B, seminal leptin, adiponectin serum/SP ratio) were available. The significance level was 0.25 for the univariate phase and 0.05 for the multivariate phase. For group comparisons, $P$ values $<0.05$ were considered statistically significant (two sides).

\section{Results}

\section{Clinical, metabolic and sperm characteristics of subjects with or without MS}

One hundred sixty men were included in the study (Fig. 1). Clinical characteristics, hormonal and metabolic status of the population studied are presented in Table 1. As expected we observed that subjects presenting MS had 
higher BMI, waist circumference, systolic and diastolic blood pressure, HOMA-IR, triglycerides, and lower HDL cholesterol.

Importantly infertility duration was higher in MS subjects (Table 1). Regarding sperm parameters, they were not different between subjects with or without MS (except $\mathrm{pH}$ ), suggesting that parameters other than those classically evaluated in the sperm can play a role.

\section{Adipokine levels in blood versus seminal plasma}

We observed that, in the entire population, the concentrations of leptin $(P<0.0001)$, adiponectin $(P<0.0001)$, resistin $(P=0.01)$, chemerin $(P<0.0001)$ and insulin $(P<0.05)$ were significantly higher in serum than in SP (Fig. 2 and Table 2). Besides, glucose levels were similar between the serum and semen. Contrarily, circulating levels of IL-6 $(P<0.0001)$ and visfatin $(P<0.0001)$ were lower in serum than in SP. These results were also found when we separated the samples into two groups, with or without MS, except for resistin, levels of which were not different in the MS group, and insulin, for which the results were not statistically significant but had a tendency to resemble the previous results.

There was a positive correlation between serum and SP for resistin $(\mathrm{rho}=0.23, P<0.05)$ and insulin $(\mathrm{rho}=0.52$, $P<0.0001)$ and no correlation for leptin, IL-6, chemerin and visfatin. Interestingly, we observed a negative correlation between serum and SP for adiponectin (rho $=-0.20, P<0.05)$.

Table 1 Characteristics of included population. Table shows clinical, biological and spermatic characteristics of the whole population included, the metabolic syndrome group (with MS) and the non-metabolic syndrome (no MS) group. $P$ value corresponds to the difference between the metabolic and non-metabolic syndrome groups.

\begin{tabular}{l} 
\\
\hline Age (years) \\
BMI (kg/m²) \\
WC (cm) \\
SBP (mmHg) \\
DBP (mmHg) \\
Infertility duration (months) \\
CO expired (\%) \\
HOMA-IR \\
Triglycerides (mmol/L) \\
Total cholesterol (mmol/L) \\
HDL cholesterol (mmol/L) \\
LDL cholesterol (mmol/L) \\
SHBG (nmol/L) \\
Total testosterone (nmol/L) \\
Bioavailable testosterone \\
$\quad$ (nmol/L) \\
Inhibin B (pg/mL) \\
FSH (UI/L) \\
LH (UI/L) \\
Estradiol (pmol/L) \\
CRP (mg/L) \\
Ejaculate volume (mL) \\
pH \\
Sperm concentration \\
$\quad\left(\times 10^{6} / \mathrm{mL}\right.$ ) \\
Total sperm count \\
Progressive motility (\%) \\
Immobility (\%) \\
Vitality (\%) \\
Normal morphology (\%) \\
DNA spermatozoa \\
$\quad$ fragmentation (\%) \\
\hline
\end{tabular}

\begin{tabular}{c}
\hline \\
\hline$n$ \\
\hline 160 \\
159 \\
157 \\
137 \\
137 \\
148 \\
145 \\
158 \\
159 \\
159 \\
159 \\
157 \\
159 \\
159 \\
147 \\
159 \\
159 \\
159 \\
159 \\
159 \\
154 \\
154 \\
154 \\
154 \\
154 \\
154 \\
148 \\
148 \\
147 \\
\\
\hline \\
\end{tabular}

\begin{tabular}{|c|c|}
\hline \multicolumn{2}{|r|}{ No MS } \\
\hline$n$ & Mean \pm S.E. \\
\hline 113 & $36.2 \pm 0.4$ \\
\hline 112 & $25.2 \pm 1.1$ \\
\hline 110 & $89.3 \pm 1.0$ \\
\hline 95 & $123.4 \pm 0.9$ \\
\hline 95 & $78.3 \pm 1$ \\
\hline 102 & $36.4 \pm 2.5$ \\
\hline 102 & $6.66 \pm 0.59$ \\
\hline 111 & $1.8 \pm 0.1$ \\
\hline 112 & $1.3 \pm 0.1$ \\
\hline 112 & $5.1 \pm 0.1$ \\
\hline 112 & $1.32 \pm 0.03$ \\
\hline 112 & $3.23 \pm 0.09$ \\
\hline 112 & $33.5 \pm 1.3$ \\
\hline 112 & $19.1 \pm 0.7$ \\
\hline 102 & $5.8 \pm 0.2$ \\
\hline 112 & $205.4 \pm 7.9$ \\
\hline 112 & $4.6 \pm 0.3$ \\
\hline 112 & $5.2 \pm 0.3$ \\
\hline 112 & $98.9 \pm 2.9$ \\
\hline 112 & $2.1 \pm 0.3$ \\
\hline 109 & $3.6 \pm 0.2$ \\
\hline 109 & $7.82 \pm 0.03$ \\
\hline 109 & $47.1 \pm 4.3$ \\
\hline 109 & $173 \pm 22$ \\
\hline 109 & $40.1 \pm 1.6$ \\
\hline 109 & $54.0 \pm 1.6$ \\
\hline 104 & $72.0 \pm 1.5$ \\
\hline 106 & $15.5 \pm 1.4$ \\
\hline 105 & $8.3 \pm 0.6$ \\
\hline
\end{tabular}

\begin{tabular}{|c|c|c|}
\hline \multicolumn{2}{|c|}{ With MS } & \multirow{2}{*}{$\begin{array}{c}\text { P value without vs } \\
\text { with MS }\end{array}$} \\
\hline$n$ & Mean \pm S.E. & \\
\hline 47 & $39.1 \pm 0.6$ & $<0.001$ \\
\hline 47 & $29.3 \pm 0.6$ & $<0.0001$ \\
\hline 47 & $101.3 \pm 1.4$ & $<0.0001$ \\
\hline 42 & $130.7 \pm 2.0$ & $<0.001$ \\
\hline 42 & $83.0 \pm 1.7$ & $<0.01$ \\
\hline 46 & $47.4 \pm 4.0$ & $<0.01$ \\
\hline 43 & $7.39 \pm 1.07$ & 0.62 \\
\hline 47 & $4.3 \pm 0.5$ & 0.001 \\
\hline 47 & $2.5 \pm 0.2$ & $<0.0001$ \\
\hline 47 & $5.4 \pm 0.2$ & 0.05 \\
\hline 47 & $1.02 \pm 0.04$ & $<0.0001$ \\
\hline 45 & $3.41 \pm 0.14$ & 0.18 \\
\hline 47 & $25.8 \pm 1.7$ & 0.0005 \\
\hline 47 & $14.5 \pm 0.8$ & $<0.0001$ \\
\hline 45 & $4.9 \pm 0.3$ & $<0.01$ \\
\hline 47 & $167.7 \pm 9.8$ & $<0.05$ \\
\hline 47 & $5.2 \pm 0.6$ & 0.40 \\
\hline 47 & $5.4 \pm 0.3$ & 0.38 \\
\hline 47 & $95.5 \pm 3.9$ & 0.78 \\
\hline 47 & $2.9 \pm 0.4$ & $<0.005$ \\
\hline 45 & $3.4 \pm 0.2$ & 0.49 \\
\hline 45 & $7.91 \pm 0.05$ & $<0.05$ \\
\hline 45 & $59.2 \pm 7.8$ & 0.09 \\
\hline 45 & $192 \pm 29$ & 0.16 \\
\hline 45 & $39.5 \pm 2.7$ & 0.89 \\
\hline 45 & $55.3 \pm 2.8$ & 0.58 \\
\hline 44 & $70.7 \pm 2.5$ & 0.72 \\
\hline 42 & $15.3 \pm 2.0$ & 0.58 \\
\hline 42 & $8.7 \pm 0.8$ & 0.33 \\
\hline
\end{tabular}

CRP, C-reactive protein; DBP, diastolic blood pressure; FSH, follicle-stimulating hormone; HOMA-IR, homeostasis assessment of insulin resistance; LH, luteinizing hormone; SBP, systolic blood pressure; SHBG, sex hormone-binding globulin; WC, waist circumference. 


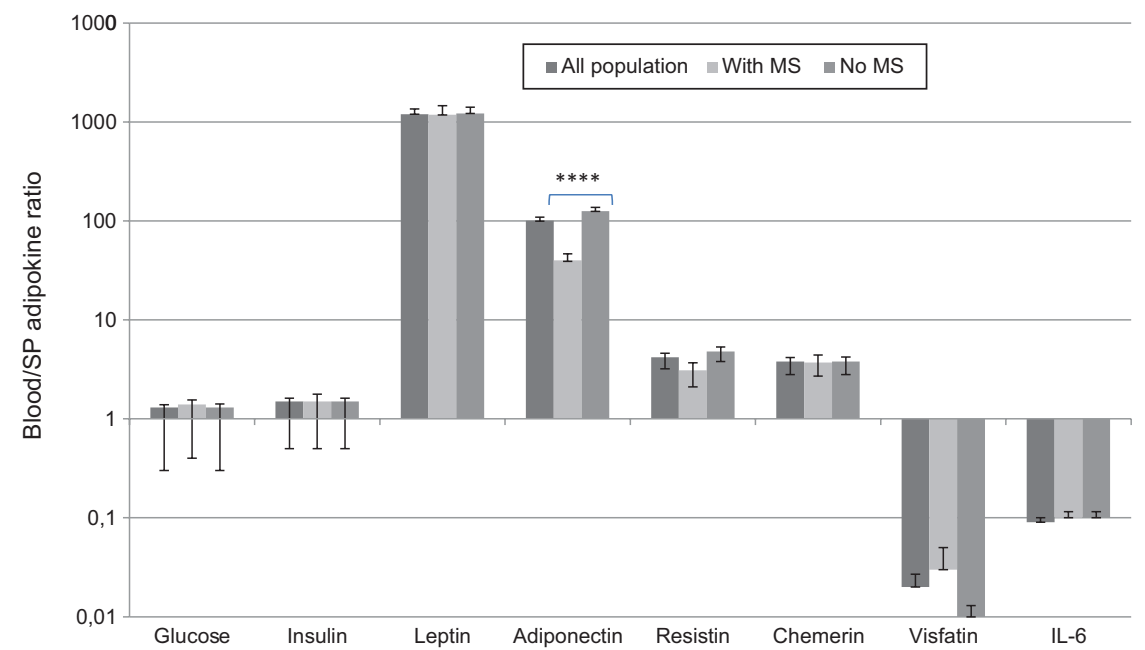

\section{Figure 2}

Ratios of the blood to seminal plasma concentration of metabolic parameters and adipokines in the entire group and in patients with and without MS. Logarithmic value of the ratio of blood/SP levels for metabolic parameters and adipokines. $* * * * P<0.0001$ : MS versus without MS.

\section{Correlations between adipokines and semen parameters}

We searched for correlations between semen parameters and adipokine values in serum and SP. Semen volume was negatively correlated with seminal visfatin $(\mathrm{rho}=-0.29$, $P<0.005)$ and seminal IL-6 (rho $=-0.24, P<0.005)$ (Table $3)$. Semen volume was also correlated with seminal glucose $($ rho $=-0.38, P<0.0005)$ and glucose serum $/ \mathrm{SP}$ ratio (rho $=0.36, P<0.0005$ ).

Sperm concentration was correlated with seminal IL-6 (rho $=0.19, P<0.05)$, seminal chemerin $(\mathrm{rho}=0.26$, $P<0.01$ ) (Table 3 ) and their serum/SP ratios (rho $=-0.25$, $P<0.005$ and rho $=-0.29, \quad P<0.005, \quad$ respectively). Sperm concentration was also correlated with seminal glucose $(\mathrm{rho}=0.22, P<0.05)$ and glucose serum/SP ratio $($ rho $=-0.20, P<0.05)$. However, when we compared subjects according to the WHO guidelines threshold ${ }^{23}$ $\left(15 \times 10^{6} / \mathrm{mL}\right.$ of spermatozoa) (32) that classifies subjects as normo- or oligo-zoospermic, we did not find any significant difference of adipokine concentration in blood or in semen (Supplementary Table 2a and b).

Progressive motility was negatively correlated with circulating IL-6 (rho $=-0.17, P<0.05$, Table 3 ) and blood/ SP ratio of IL-6 (rho $=-0.29, P<0.001)$, whereas it was positively related to seminal IL-6 (rho $=0.23, P<0.01$, Table 3). By comparing patients according to normal progressive motility (higher than $32 \%$ according to WHO guidelines (32)), we confirmed the increase of circulating IL-6 $(P<0.05)$ (Supplementary Table 2a) and of IL-6 serum/ SP ratio (0.091 (0.037-0.139) vs 0.045 (0.023-0.102), $P=0.01)$ in asthenospermic subjects.

Sperm vitality was negatively correlated to IL-6 blood/ SP ratio $($ rho $=-0.23, P<0.01)$ and positively related to seminal IL-6 (rho $=0.17, P<0.05)$ (Table 3$)$. When we compared patients according to normal vitality threshold (threshold 58\%, WHO guidelines (32)), we confirmed the increase of IL-6 blood/SP ratio (0.100 (0.044-0.168) vs $0.051(0.024-0.105), P=0.01)$ and the decrease of seminal IL-6 $(P<0.05)$ in subjects with necrospermia (Supplementary Table 2a).

Altogether, these results emphasize the relationship between IL-6 in SP and semen parameters and supports a favorable effect of the locally present IL-6. Conversely, circulating IL-6 is negatively related to sperm quality. Likewise, sperm concentration, total count and motility are correlated with CRP $(\mathrm{rho}=-0.17, P<0.05 ; \mathrm{rho}=-0.22$, $P<0.01$ and rho $=-0.24, P<0.005$ respectively), further stressing a negative impact of circulating low-grade inflammation on fertility in men.

Sperm morphology did not correlate with any adipokine levels neither in blood, nor in SP (Table 3).

\section{Relationships between blood and seminal adipokines according to the MS status}

In our population, $29.4 \%$ of subjects presented a MS (Table 1), with 47 patients with MS and 113 without MS.

As expected, we detected higher circulating levels of insulin, leptin and IL- 6 and by contrast lower adiponectin levels in individuals with MS compared to those without MS (Table 2). In SP, we observed higher seminal concentrations of leptin $(P<0.005)$, resistin $(P<0.005)$ and insulin $(P<0.0001)$ in the MS group than in the non-MS group (Table 2). Interestingly, while serum adiponectin levels were lower in the MS group (3.1 vs $4.0 \mathrm{mg} / \mathrm{L}, P<0.0001)$, the opposite was seen in the SP, with adiponectin levels being 2.1-fold higher $(P<0.0001)$ in patients with MS (Table 2$)$. The specificity of the adiponectin pattern was also seen when the results were expressed as blood/SP adipokine 


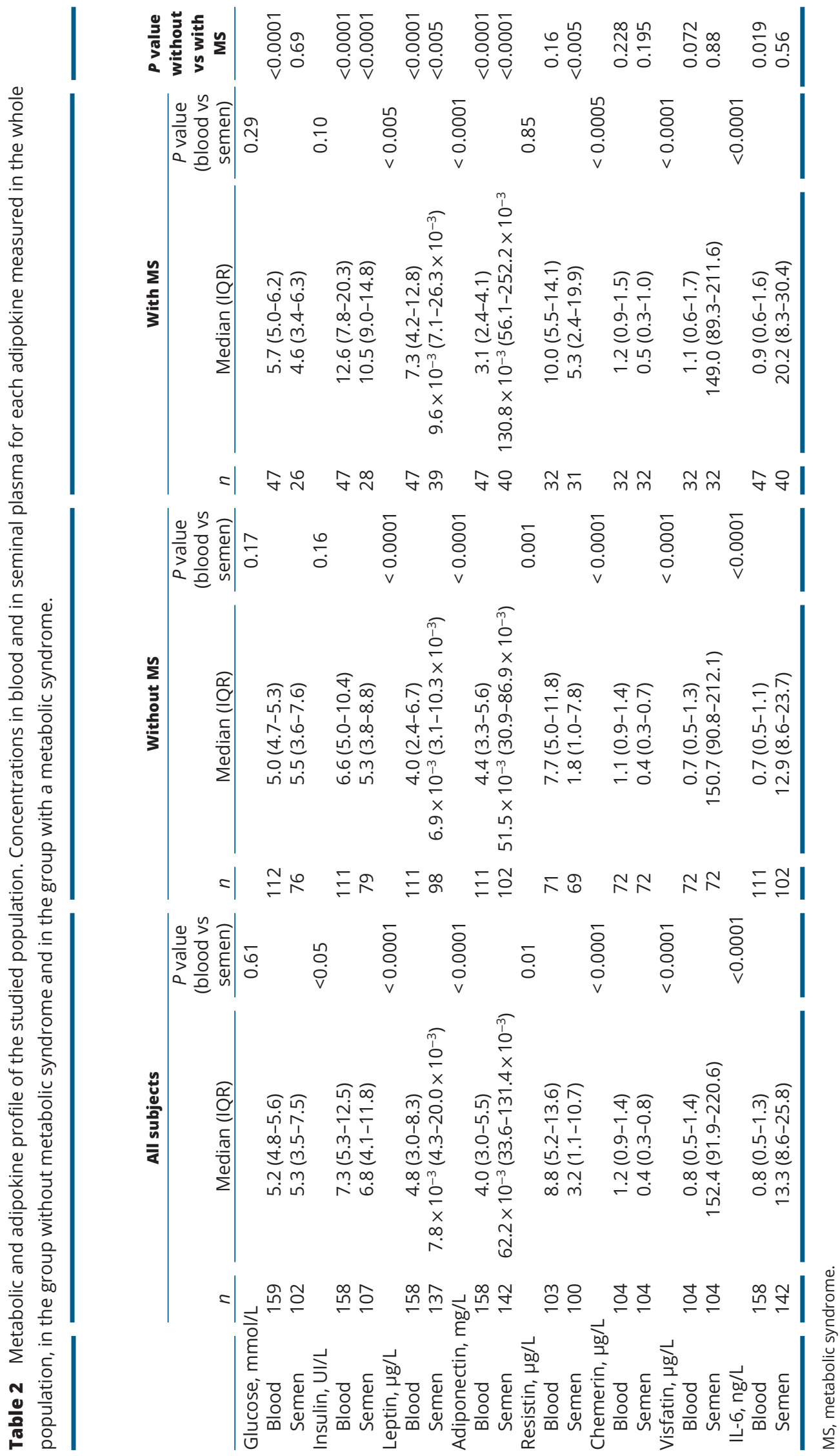


Table 3 Correlations between adipokines and semen parameters.

\begin{tabular}{|c|c|c|c|c|c|c|c|c|c|c|c|c|}
\hline \multirow{2}{*}{$\begin{array}{l}\text { Sperm } \\
\text { parameters }\end{array}$} & \multicolumn{2}{|c|}{ Leptin } & \multicolumn{2}{|c|}{ Adiponectin } & \multicolumn{2}{|c|}{ II-6 } & \multicolumn{2}{|c|}{ Resistin } & \multicolumn{2}{|c|}{ Chemerin } & \multicolumn{2}{|c|}{ Visfatin } \\
\hline & Blood & $\mathrm{SP}$ & Blood & $\mathrm{SP}$ & Blood & $\mathrm{SP}$ & Blood & $\mathrm{SP}$ & Blood & $\mathrm{SP}$ & Blood & $\mathrm{SP}$ \\
\hline \multicolumn{13}{|l|}{ Volume } \\
\hline rho & -0.04 & 0.06 & 0.01 & -0.08 & -0.10 & -0.24 & 0.02 & -0.11 & 0.01 & -0.18 & -0.05 & -0.29 \\
\hline$P$ & 0.64 & 0.52 & 0.91 & 0.33 & 0.21 & $<0.005$ & 0.86 & 0.25 & 0.94 & 0.06 & 0.60 & $<0.005$ \\
\hline \multicolumn{13}{|c|}{ Sperm concentration } \\
\hline rho & -0.05 & 0.08 & -0.04 & 0.01 & -0.15 & 0.19 & 0.04 & -0.08 & -0.11 & 0.26 & -0.10 & 0.14 \\
\hline P & 0.53 & 0.33 & 0.59 & 0.90 & 0.06 & $<0.05$ & 0.65 & 0.42 & 0.25 & $<0.01$ & 0.33 & 0.14 \\
\hline \multicolumn{13}{|l|}{ Sperm count } \\
\hline rho & -0.04 & 0.11 & -0.02 & 0.01 & -0.17 & 0.08 & 0.04 & -0.12 & -0.09 & 0.14 & -0.12 & -0.01 \\
\hline$P$ & 0.57 & 0.19 & 0.80 & 0.95 & $<0.05$ & 0.36 & 0.71 & 0.25 & 0.36 & 0.14 & 0.22 & 0.92 \\
\hline \multicolumn{13}{|c|}{ Progressive mobility } \\
\hline rho & -0.12 & -0.05 & 0.08 & 0.04 & -0.17 & 0.23 & -0.14 & 0.02 & -0.12 & 0.13 & -0.04 & 0.05 \\
\hline$P$ & 0.12 & 0.50 & 0.37 & 0.69 & $<0.05$ & $<0.01$ & 0.15 & 0.85 & 0.22 & 0.20 & 0.67 & 0.65 \\
\hline \multicolumn{13}{|l|}{ Vitality } \\
\hline rho & 0.01 & -0.05 & 0.13 & 0.08 & -0.08 & 0.17 & -0.18 & 0.03 & -0.05 & 0.09 & 0.02 & 0.08 \\
\hline$P$ & 0.96 & 0.54 & 0.13 & 0.38 & 0.31 & $<0.05$ & 0.07 & 0.80 & 0.62 & 0.39 & 0.82 & 0.43 \\
\hline \multicolumn{13}{|c|}{ Typical forms } \\
\hline rho & -0.02 & 0.02 & 0.04 & -0.03 & -0.07 & 0.10 & -0.17 & 0.06 & -0.08 & -0.01 & -0.19 & 0.11 \\
\hline$P$ & 0.79 & 0.81 & 0.61 & 0.74 & 0.36 & 0.22 & 0.09 & 0.53 & 0.42 & 0.97 & 0.06 & 0.28 \\
\hline
\end{tabular}

Statistically significant values are indicated in bold characters.

ratio (Fig. 2), blood/SP adiponectin ratio being higher in individuals without MS compared to those with MS.

To discriminate major parameters independently correlated to MS, we performed statistical logistic regression analysis including nine parameters (age, infertility time, sperm concentration, BMI, SHBG, total testosteronemia, inhibin $\mathrm{B}$, seminal leptin, adiponectin serum/SP ratio) statistically different between the subjects with and without MS (Supplementary Table 3). The analysis shows that three parameters were independently associated to MS $\left(r^{2}=0.27\right)$ : BMI $(\mathrm{OR}=1.2,95 \% \mathrm{CI}=1.046-$ 1.377, $P<0.01)$, infertility duration $(\mathrm{OR}=1.017,95 \%$ $\mathrm{CI}=1.0-1.034, P<0.05)$, and adiponectin serum/SP ratio $(\mathrm{OR}=0.986,95 \% \mathrm{CI}=0.976-0.996, P<0.01)$ (Table 4).

\section{Discussion}

Our study aimed to identify the potential relationships between circulating or SP adipokines and semen

Table 4 Logistic regression for multivariate analysis demonstrating factors independently correlated to MS $\left(n=132, r^{2}=0.27\right)$.

\begin{tabular}{|c|c|c|c|}
\hline & OR & $P$ value & $95 \% \mathrm{Cl}$ \\
\hline Infertility duration & 1.017 & 0.0465 & 1.0-1.034 \\
\hline $\mathrm{BMI}$ & 1.200 & 0.0094 & $1.046-1.377$ \\
\hline $\begin{array}{l}\text { Adiponectin } \\
\text { blood/SP ratio }\end{array}$ & 0.986 & 0.0074 & $0.976-0.996$ \\
\hline
\end{tabular}

MS, metabolic syndrome; SP, seminal plasma. parameters, and whether they were influenced by the metabolic status of male partners from infertile couples. To perform this work, we carried out a preliminary study to optimize the pre-analytical conditions for adipokine assays in SP, since this is a challenging and critical point. We validated a method that allowed us to obtain an homogeneous seminal fluid leading to excellent repeatability and reproducibility of the essays, comparable to those described by the manufacturers for blood samples (37).

Our study shows that all adipokines studied were present in SP. Most of them were higher in the blood than in the semen in the whole population (Fig. 2 ). This observation suggests that these adipokines could diffuse from the blood into the SP compartment, but we could not eliminate the possibility of a local production by the genital tracts. The opposite situation was observed for IL-6 and visfatin with higher concentrations in the SP than in the circulation, suggesting a local production. Accordingly, some studies revealed that Sertoli cells, Leydig cells and even germ cells produce IL-6 $(39,40)$. Furthermore, visfatin (nicotinamide phosphoribosyltransferase or NAMPT) is present and also released from human spermatozoa (41).

Regarding the MS, it can be pointed that $29.4 \%$ of the included men presented a MS, whereas this is the case for only $17.5 \%$ of French men aged from 18 to 50 years (42). This difference was also reported in a recent study showing that MS was more prevalent in male partners of infertile couples than in documented fertile men (17). Strikingly, we showed that men from infertile couples with MS had 
a particularly long infertility period compared to those without MS (Tables 1 and 4). This strengthens the concept that the MS could impact male fertility. Thus, it could be useful to detect these patients early on in order to target a specific therapeutic management of their MS to improve their fertility. Indeed, some studies have shown that men exercising moderate physical activity had better sperm parameters than sedentary men $(43,44)$. Other studies have shown better sperm parameters in cases of strong adherence to a healthy diet $(45,46)$. In addition, a recent study showed that coaching a couple on lifestyle and diet during the pre-pregnancy period increased the pregnancy rate (47). Thus, it is tempting to speculate that improving MS through dietary and physical interventions will likely have a beneficial effect on sperm parameters and fertility.

The differences obtained in the concentrations of the different adipokines between SP and blood (Fig. 2) agree with the scarce data previously published $(24,48,49)$. As reported, we didn't find any correlations between the two matrices for leptin, chemerin and visfatin (24). The blood/ SP adipokine ratios were not different between individuals with or without MS, except for the blood/SP adiponectin ratio that was three-fold lower in subjects with MS as compared to those without MS. As expected, we found lower circulating adiponectin levels in the MS group than in the non-MS group (50). Unexpectedly, we observed an increase of SP adiponectin and subsequently a decrease of the adiponectin blood/SP ratio in the MS group compared to the non-MS group. Several hypotheses could be proposed to explain this increase of adiponectin in SP in patients with MS. First, there could be a local production of seminal adiponectin. Indeed, adiponectin receptors are expressed in human testes including the Leydig cells but also in the epididymis, and spermatozoa, and adiponectin is expressed in Leydig cells $(51,52,53)$ even if, to the best of our knowledge, there is no indication of adiponectin production by the genital male tract up to now. Secondly, there could be an active or facilitated uptake of adiponectin from the blood to the seminal compartment. A recent study showed a decrease in tight junctions at the blood-testis barrier in mice infused intra-peritoneally by recombinant leptin (54). Considering the increased circulating leptin concentrations in patients with MS, it is conceivable that this leptin-induced disturbance in blood-testis barrier permeability could contribute to increased adiponectin transfer toward the SP. Finally, another possibility is that adiponectin could be protected from degradation in the SP compartment, with a slower turn-over. Our results indicate that increased adiponectin in the SP was observed in MS subjects with poorer fertility. As well, discordant data regarding the beneficial effect of adiponectin was reported in the cardiometabolic field. Indeed, it has been shown that, while low levels of circulating adiponectin are generally considered as a cardiovascular risk factor, a pejorative cardiovascular outcome was reported in subjects with high adiponectin plasma value (55). Whatever the explanations of the increased SP adiponectin concentration in subjects with MS, there was no correlation between the levels of this adipokine and semen parameters, raising the possibility that adiponectin could act beyond these parameters on male fertility.

In contrast with other adipokines, we observed significant and inverse relationships between SP and plasma IL-6 levels and sperm parameters. Circulating IL-6 is usually considered as a biomarker of inflammation that would be rather deleterious and associated with infertility (56). Consistent with this concept, we found a negative correlation between circulating IL- 6 and the number and motility of spermatozoa. Accordingly, CRP level was also negatively associated with sperm quality parameters stressing for a deleterious impact of low-grade systemic inflammation.

By contrast, we found a positive and perhaps a beneficial association between seminal IL-6, and functional parameters of sperm that could be linked to the non-inflammatory effect of IL-6, previously described for the skeletal muscle (57). Indeed, IL-6 was shown as a beneficial factor on metabolism when secreted by muscle under exercise and fasting, whereas it was deleterious when secreted by adipose tissue during inflammatory processes as observed in the context of obesity (58, 59). IL-6 effects on muscle cells have been reported to be mediated by activation of AMPK (5'adenosine monophosphate-activated protein kinase) (58). The active phosphorylated form of AMPK (phospho-AMPK-Thr172) has been identified in pig, horse, mouse, rooster and human sperm, and particularly on the whole flagellum and acrosome for roosters, which suggests an important role in motility and acrosomal reaction $(60,61)$. AMPK is involved in the modulation of the nutritional function of the germ line by increasing the lactate production of Sertoli cells in response to an increase of glucose uptake (62), which could explain the positive association between IL-6 and sperm concentration. In addition, mice KO for AMPK $\alpha 1$ become asthenospermic (63), an observation in agreement with the positive correlation we observed between IL- 6 and sperm motility. AMPK would act by phosphorylation of the protein substrates involved in 
the functioning of the central apparatus of the axoneme, which are essential for flagellar motility (64).

The findings of our study should be interpreted within certain limitations. The volume of the ejaculate is a factor limiting the number of assays that could be performed, which explains the disparity between adipokines in the number of both assays and analyses. Otherwise, there are frequent intra-individual variations between semen samples. However, to make the link between the blood and seminal parameters, it was important to collect blood and semen concomitantly. Another limitation is the absence of proven fertile control men. However, when comparing men with a previous fertility ( $n=35$ for subjects without MS and $n=17$ for subjects with MS), we retrieved our main results i.e. an increase of SP adiponectin in patients with MS $(P<0.005)$ and a positive trend between seminal IL- 6 levels and sperm vitality $(P=0.05)$. In addition, men with MS had lower testosterone levels as expected, but hormonal measurements were not performed by mass spectrometry and may thus be inaccurate at low concentrations. This result needs, therefore, to be interpreted with caution. Finally, we present an observational study, which does not allow mechanistic insights. However, despite these limitations, this study included a well-defined cohort of 160 subjects.

We found an independent association between MS in male partners of infertile couples and BMI, adiponectin serum/SP ratio and infertility time (Table 4) suggesting the importance of MS in male fertility. The data found on SP IL-6 suggest a potentially beneficial role of seminal IL-6 on progressive motility, sperm vitality, and sperm concentration. However, mechanistic studies are now needed to further investigate the local effects of IL- 6 and adiponectin on male reproductive function in MS.

\section{Supplementary materials}

This is linked to the online version of the paper at https://doi.org/10.1530/ EJE-19-0615.

\section{Declaration of interest}

The authors declare that there is no conflict of interest that could be perceived as prejudicing the impartiality of this study.

\section{Funding}

This work was supported by the Programme Hospitalier de Recherche Clinique (PHRC number AOM 10020-NI 10033-ID-RCB 2011-A0105239), the Agence de Biomedicine Project 'Adipocytokines' (grant number 32000822), la Fondation pour la Recherche Médicale (EQU201903007868), Assistance Publique Publique de Hôpitaux de Paris, Sorbonne University and INSERM.

\section{Author contribution statement}

$B$ F, R L, and J-P B conceived and designed the study. Y E, A B, S F, C F, C M, and J-P B performed most of the experiments. $P L, F F$, and J-P B performed the statistical analysis. J C, J D, and R L critically revised the manuscript. B F and J-P B wrote the manuscript.

\section{Acknowledgements}

The authors thank Ginette Marlin and Elodie Heude for their technical support.

The Metasperme group consisted of: Rachel Levy, Céline Faure, Nathalie Sermondade, Florence Eustache, Myriam Benarroch, Charlotte Dupont, Isabelle Cedrin, Vanina De Larouzière, Emmanuelle Mathieu D'Argent, Angela Sutton, Jérôme Guechot and Sébastien Czernichow.

\section{References}

1 NCD Risk Factor Collaboration (NCD-RisC). Trends in adult bodymass index in 200 countries from 1975 to 2014: a pooled analysis of 1698 population-based measurement studies with 19.2 million participants. Lancet 2016387 1377-1396. (https://doi.org/10.1016/ S0140-6736(16)30054-X)

2 Martins AD, Majzoub A \& Agawal A. Metabolic syndrome and male fertility. World Journal of Men's Health 201837 113-127. (https://doi. org/10.5534/wjmh.180055)

3 Ng M, Fleming T, Robinson M, Thomson B, Graetz N, Margono C, Mullany EC, Biryukov S, Abbafati C, Abera SF et al. Global, regional and national prevalence of overweight and obesity in children and adults 1980-2013: a systematic analysis. Lancet $2014 \mathbf{3 8 4} 766-781$. (https://doi.org/10.1016/S0140-6736(14)60460-8)

4 Moore JX, Chaudhary N \& Akinyemiju T. Metabolic syndrome prevalence by race/ethnicity and sex in the United States, National Health and Nutrition Examination Survey, 1988-2012. Preventing Chronic Disease 2017 14 E24. (https://doi.org/10.5888/pcd14.160287)

5 Thonneau P, Marchand S, Tallec A, Ferial ML, Ducot B, Lansac J, Lopes P, Tabaste JM \& Spira A. Incidence and main causes of infertility in a resident population $(1,850,000)$ of three French regions (1988-1989). Human Reproduction 19916 811-816. (https:// doi.org/10.1093/oxfordjournals.humrep.a137433)

6 Vander Borght M \& Wyns C. Fertility and infertility: definition and epidemiology. Clinical Biochemistry 201862 2-10. (https://doi. org/10.1016/j.clinbiochem.2018.03.012)

7 Rumbold AR, Sevoyan A, Oswald TK, Fernandez RC, Davies MJ \& Moore VM. Impact of male factor infertility on offspring health and development. Fertility and Sterility 2019111 1047-1053. (https://doi. org/10.1016/j.fertnstert.2019.05.006)

8 Leung AK, Henry MA \& Mehta A. Gaps in male infertility health services research. Translational Andrology and Urology 20187 S303-S309. (https://doi.org/10.21037/tau.2018.05.03)

9 Sengupta P, Borges E, Dutta S \& Krajewska-Kulak E. Decline in sperm count in European men during the past 50 years. Human and Experimental Toxicology 201837 247-255. (https://doi. org/10.1177/0960327117703690)

10 Levine H, Jørgensen N, Martino-Andrade A, Mendiola J, WekslerDerri D, Mindlis I, Pinotti R \& Swan SH. Temporal trends in sperm count: a systematic review and meta-regression analysis. Human Reproduction Update 201723 646-659. (https://doi.org/10.1093/ humupd/dmx022)

11 Carrageta DF, Oliveira PF, Alves MG \& Monteiro MP. Obesity and male hypogonadism: tales of a vicious cycle. Obesity Reviews 201920 1148-1158. (https://doi.org/10.1111/obr.12863)

12 Lotti F, Corona G, Degli Innocenti S, Filimberti E, Scognamiglio V, Vignozzi L, Forti G \& Maggi M. Seminal, ultrasound and psychobiological parameters correlate with metabolic syndrome 
in male members of infertile couples. Andrology $20131229-239$. (https://doi.org/10.1111/j.2047-2927.2012.00031.x)

13 Ventimiglia E, Capogrosso P, Colicchia M, Boeri L, Serino A, Castagna G, Clementi MC, La Croce G, Regina C, Bianchi M et al. Metabolic syndrome in white European men presenting for primary couple's infertility: investigation of the clinical and reproductive burden. Andrology 20164 944-951. (https://doi.org/10.1111/ andr.12232)

14 Ventimiglia E, Capogrosso P, Serino A, Boeri L, Colicchia M, La Croce G, Scano R, Papaleo E, Damiano R, Montorsi F et al. Metabolic syndrome in White-European men presenting for secondary couple's infertility: an investigation of the clinical and reproductive burden. Asian Journal of Andrology 201719 368-373. (https://doi. org/10.4103/1008-682X.175783)

15 Corona G, Mannucci E, Schulman C, Petrone L, Mansani R, Cilotti A, Balercia G, Chiarini V, Forti G \& Maggi M. Psychobiologic correlates of the metabolic syndrome and associated sexual dysfunction. European Urology 200650 595-604; discussion 604. (https://doi. org/10.1016/j.eururo.2006.02.053)

16 Leisegang K, Udodong A, Bouic PJD \& Henkel RR. Effect of the metabolic syndrome on male reproductive function: a casecontrolled pilot study. Andrologia 201446 167-176. (https://doi. org/10.1111/and.12060)

17 Ehala-Aleksejev K \& Punab M. The effect of metabolic syndrome on male reproductive health: a cross-sectional study in a group of fertile men and male partners of infertile couples. PLoS ONE 201813 e0194395. (https://doi.org/10.1371/journal.pone.0194395)

18 Leisegang K, Bouic PJD \& Henkel RR. Metabolic syndrome is associated with increased seminal inflammatory cytokines and reproductive dysfunction in a case-controlled male cohort. American Journal of Reproductive Immunology 201676 155-163. (https://doi. org/10.1111/aji.12529)

19 Pilatz A, Hudemann C, Wolf J, Halefeld I, Paradowska-Dogan A, Schuppe HC, Hossain H, Jiang Q, Schultheiss D, Renz H et al. Metabolic syndrome and the seminal cytokine network in morbidly obese males. Andrology 20175 23-30. (https://doi.org/10.1111/ andr.12296)

20 Manna P \& Jain SK. Obesity, oxidative stress, adipose tissue dysfunction, and the associated health risks: causes and therapeutic strategies. Metabolic Syndrome and Related Disorders 201513 423-444. (https://doi.org/10.1089/met.2015.0095)

21 Chu Y, Huddleston GG, Clancy AN, Harris RBS \& Bartness TJ. Epididymal fat is necessary for spermatogenesis, but not testosterone production or copulatory behavior. Endocrinology 2010151 5669-5679. (https://doi.org/10.1210/en.2010-0772)

22 Elfassy Y, McAvoy C, Fellahi S, Dupont J, Fève B, Levy R \& Bastard JP. Seminal plasma adipokines: involvement in human reproductive functions. European Cytokine Network 201728 141-150. (https://doi. $\operatorname{org} / 10.1684 /$ ecn.2018.0403)

23 Al Maskari MY \& Alnaqdy AA. Correlation between serum leptin levels, body mass index and obesity in Omanis. Sultan Qaboos University Medical Journal 20066 27-31.

24 Thomas S, Kratzsch D, Schaab M, Scholz M, Grunewald S, Thiery J, Paasch U \& Kratzsch J. Seminal plasma adipokine levels are correlated with functional characteristics of spermatozoa. Fertility and Sterility 201399 1256-1263.e3. (https://doi.org/10.1016/j. fertnstert.2012.12.022)

25 Hofny ERM, Ali ME, Abdel-Hafez HZ, Kamal Eel-D, Mohamed EE, Abd El-Azeem HG \& Mostafa T. Semen parameters and hormonal profile in obese fertile and infertile males. Fertility and Sterility 2010 94 581-584. (https://doi.org/10.1016/j.fertnstert.2009.03.085)

26 Kim N, Nakamura H, Masaki H, Kumasawa K, Hirano KI \& Kimura T. Effect of lipid metabolism on male fertility. Biochemical and Biophysical Research Communications 2017485 686-692. (https://doi. org/10.1016/j.bbrc.2017.02.103)
27 Alves MG, Jesus TT, Sousa M, Goldberg E, Silva BM \& Oliveira PF. Male fertility and obesity: are ghrelin, leptin and glucagon-like peptide-1 pharmacologically relevant? Current Pharmaceutical Design 201622 783-791. (https://doi.org/10.2174/1381612822666 151209151550)

28 Kasimanickam VR, Kasimanickam RK, Kastelic JP \& Stevenson JS. Associations of adiponectin and fertility estimates in Holstein bulls. Theriogenology 201379 766-77.e1. (https://doi.org/10.1016/j. theriogenology.2012.12.001)

29 Elfassy Y, Bastard JP, McAvoy C, Fellahi S, Dupont J \& Levy R. Adipokines in semen: physiopathology and effects on spermatozoas. International Journal of Endocrinology 20182018 3906490. (https:// doi.org/10.1155/2018/3906490)

30 Waist Circumference and Waist-Hip Ratio: Report of a WHO Expert Consultation, Geneva, 8-11 December 2008.

31 L'analyse de routine du sperme (spermogramme et spermocytogramme). In Cahier de formation biologie médicale : Exploration de la fonction de la reproduction versant masculine, n42, ch. 3, pp 40-93. Cahier BIOFORMA, 2009.

32 Cooper TG, Noonan E, von Eckardstein S, Auger J, Baker HWG, Behre HM, Haugen TB, Kruger T, Wang C, Mbizvo MT et al. World Health Organization reference values for human semen characteristics. Human Reproduction Update 201016 231-245. (https://doi.org/10.1093/humupd/dmp048)

33 Auger J, Eustache F \& David G. Standardisation de la classification morphologique des spermatozoïdes humains selon la méthode de David modifiée. Andrologie 200010 358-373. (https://doi. org/10.1007/BF03034491)

34 Loric S, Guéchot J, Duron F, Aubert P \& Giboudeau J. Determination of testosterone in serum not bound by sex-hormone-binding globulin: diagnostic value in hirsute women. Clinical Chemistry 1988 34 1826-1829.

35 Giton F, Fiet J, Guéchot J, Ibrahim F, Bronsard F, Chopin D \& Raynaud JP. Serum bioavailable testosterone: assayed or calculated? Clinical Chemistry 200652 474-481. (https://doi.org/10.1373/ clinchem.2005.052126)

36 Matthews DR, Hosker JP, Rudenski AS, Naylor BA, Treacher DF \& Turner RC. Homeostasis model assessment: insulin resistance and beta-cell function from fasting plasma glucose and insulin concentrations in man. Diabetologia 198528 412-419. (https://doi. org/10.1007/bf00280883)

37 Elfassy Y, McAvoy C, Fellahi S, Berthaut I, Capeau J, Dupont J, Fève B, Levy R \& Bastard JP. Optimization of pre-analytical conditions for measurement of biomarkers in seminal plasma: application to adipokines. Annales De Biologie Clinique 201775 715-717. (https:// doi.org/10.1684/abc.2017.1292)

38 Alberti KGMM, Eckel RH, Grundy SM, Zimmet PZ, Cleeman JI, Donato KA, Fruchart JC, James WPT, Loria CM, Smith SC et al. Harmonizing the metabolic syndrome: a joint interim statement of the International Diabetes Federation Task Force on Epidemiology and Prevention; National Heart, Lung, and Blood Institute; American Heart Association; World Heart Federation; International Atherosclerosis Society; and International Association for the Study of Obesity. Circulation 2009120 1640-1645. (https://doi. org/10.1161/CIRCULATIONAHA.109.192644)

39 Cudicini C, Lejeune H, Gomez E, Bosmans E, Ballet F, Saez J \& Jégou B. Human Leydig cells and Sertoli cells are producers of interleukins-1 and -6. Journal of Clinical Endocrinology and Metabolism 199782 1426-1433. (https://doi.org/10.1210/jcem.82.5.3938)

40 Jégou B, Cudicini C, Gomez E \& Stéphan JP. Interleukin-1, interleukin-6 and the germ cell-Sertoli cell cross-talk. Reproduction, Fertility, and Development 19957 723-730. (https://doi.org/10.1071/ rd9950723)

41 Riammer S, Garten A, Schaab M, Grunewald S, Kiess W, Kratzsch J $\&$ Paasch U. Nicotinamide phosphoribosyltransferase production in 
human spermatozoa is influenced by maturation stage. Andrology 20164 1045-1053. (https://doi.org/10.1111/andr.12252)

42 Vernay M, Salanave B, de Peretti C, Druet C, Malon A, Deschamps V, Hercberg S \& Castetbon K. Metabolic syndrome and socioeconomic status in France: the French Nutrition and Health Survey (ENNS, 2006-2007). International Journal of Public Health 201358 855-864. (https://doi.org/10.1007/s00038-013-0501-2)

43 Vaamonde D, Da Silva-Grigoletto ME, García-Manso JM, Barrera N $\&$ Vaamonde-Lemos R. Physically active men show better semen parameters and hormone values than sedentary men. European Journal of Applied Physiology 2012112 3267-3273. (https://doi. org/10.1007/s00421-011-2304-6)

44 Gaskins AJ, Afeiche MC, Hauser R, Williams PL, Gillman MW, Tanrikut C, Petrozza JC \& Chavarro JE. Paternal physical and sedentary activities in relation to semen quality and reproductive outcomes among couples from a fertility center. Human Reproduction 201429 2575-2582. (https://doi.org/10.1093/humrep/deu212)

45 Oostingh EC, Steegers-Theunissen RPM, de Vries JHM, Laven JSE $\&$ Koster MPH. Strong adherence to a healthy dietary pattern is associated with better semen quality, especially in men with poor semen quality. Fertility and Sterility 2017107 916.e2-923.e2. (https:// doi.org/10.1016/j.fertnstert.2017.02.103)

46 Cutillas-Tolín A, Mínguez-Alarcón L, Mendiola J, López-Espín JJ, Jørgensen N, Navarrete-Muñoz EM, Torres-Cantero AM \& Chavarro JE. Mediterranean and western dietary patterns are related to markers of testicular function among healthy men. Human Reproduction 201530 2945-2955. (https://doi.org/10.1093/humrep/ dev236)

47 van Dijk MR, Koster MPH, Willemsen SP, Huijgen NA, Laven JSE \& Steegers-Theunissen RPM. Healthy preconception nutrition and lifestyle using personalized mobile health coaching is associated with enhanced pregnancy chance. Reproductive Biomedicine Online 201735 453-460. (https://doi.org/10.1016/j.rbmo.2017.06.014)

48 Leisegang K, Bouic PJD, Menkveld R \& Henkel RR. Obesity is associated with increased seminal insulin and leptin alongside reduced fertility parameters in a controlled male cohort. Reproductive Biology and Endocrinology 201412 34. (https://doi.org/10.1186/14777827-12-34)

49 Bongrani A, Elfassy Y, Brun JS, Ramé C, Mellouk N, Fellahi S, Bastard JP, Levy R, Vasseur C, Froment P et al. Expression of adipokines in seminal fluid of men of normal weight. Asian Journal of Andrology 201921 528-530. (https://doi.org/10.4103/aja.aja_25_19)

50 von Frankenberg ADV, Reis AF \& Gerchman F. Relationships between adiponectin levels, the metabolic syndrome, and type 2 diabetes: a literature review. Archives of Endocrinology and Metabolism 201761 614-622. (https://doi.org/10.1590/2359-3997000000316)

51 Civitarese AE, Jenkinson CP, Richardson D, Bajaj M, Cusi K, Kashyap S, Berria R, Belfort R, DeFronzo RA, Mandarino LJ et al. Adiponectin receptors gene expression and insulin sensitivity in nondiabetic Mexican Americans with or without a family history of Type 2 diabetes. Diabetologia 200447 816-820. (https://doi.org/10.1007/ s00125-004-1359-x)
52 Caminos JE, Nogueiras R, Gaytán F, Pineda R, González CR, Barreiro ML, Castaño JP, Malagón MM, Pinilla L, Toppari J et al. Novel expression and direct effects of adiponectin in the rat testis. Endocrinology 2008149 3390-3402. (https://doi.org/10.1210/ en.2007-1582)

53 Martin LJ. Implications of adiponectin in linking metabolism to testicular function. Endocrine 201446 16-28. (https://doi. org/10.1007/s12020-013-0102-0)

54 Wang X, Zhang X, Hu L \& Li H. Exogenous leptin affects sperm parameters and impairs blood testis barrier integrity in adult male mice. Reproductive Biology and Endocrinology 201816 55. (https://doi. org/10.1186/s12958-018-0368-4)

55 Hascoet S, Elbaz M, Bongard V, Bouisset F, Verdier C, Vindis C, Genoux A, Taraszkiewicz D, Perret B, Galinier M et al. Adiponectin and long-term mortality in coronary artery disease participants and controls. Arteriosclerosis, Thrombosis, and Vascular Biology 201333 e19-e29. (https://doi.org/10.1161/ATVBAHA.112.300079)

56 Hærvig KK, Kierkegaard L, Lund R, Bruunsgaard H, Osler M \& Schmidt L. Is male factor infertility associated with midlife low-grade inflammation? A population based study. Human Fertility 201821 146-154. (https://doi.org/10.1080/14647273.2017.1323278)

57 Pedersen BK \& Febbraio MA. Muscles, exercise and obesity: skeletal muscle as a secretory organ. Nature Reviews: Endocrinology 20128 457-465. (https://doi.org/10.1038/nrendo.2012.49)

58 Ghanemi A \& St-Amand J. Interleukin-6 as a 'metabolic hormone'. Cytokine 2018112 132-136. (https://doi.org/10.1016/j. cyto.2018.06.034)

59 Fève B \& Bastard JP. The role of interleukins in insulin resistance and type 2 diabetes mellitus. Nature Reviews: Endocrinology 20095 305-311. (https://doi.org/10.1038/nrendo.2009.62)

60 Nguyen TMD, Froment P, Combarnous Y \& Blesbois É. AMPK, regulator of sperm energy and functions. Medecine Sciences 201632 491-496. (https://doi.org/10.1051/medsci/20163205016)

61 Calle-Guisado V, de Llera AH, Martin-Hidalgo D, Mijares J, Gil MC, Alvarez IS, Bragado MJ \& Garcia-Marin LJ. AMP-activated kinase in human spermatozoa: identification, intracellular localization, and key function in the regulation of sperm motility. Asian Journal of Andrology 201719 707-714. (https://doi.org/10.4103/1008682X.185848)

62 Guévélou E, Huvet A, Galindo-Sánchez CE, Milan M, Quillien V, Daniel JY, Quéré C, Boudry P \& Corporeau C. Sex-specific regulation of AMP-activated protein kinase (AMPK) in the Pacific oyster Crassostrea gigas. Biology of Reproduction 201389 100. (https://doi. org/10.1095/biolreprod.113.109728)

63 Towler MC, Fogarty S, Hawley SA, Pan DA, Martin DMA, Morrice NA, McCarthy A, Galardo MN, Meroni SB, Cigorraga SB et al. A novel short splice variant of the tumour suppressor LKB1 is required for spermiogenesis. Biochemical Journal 2008416 1-14. (https://doi. org/10.1042/BJ20081447)

64 Nguyen TMD. Impact of 5'-amp-activated protein kinase on male gonad and spermatozoa functions. Frontiers in Cell and Developmental Biology 20175 25. (https://doi.org/10.3389/fcell.2017.00025)

Received 6 August 2019

Revised version received 31 October 2019

Accepted 7 November 2019 